\title{
Mees lines and Beau lines after chemotherapy
}

\author{
Tzu-Chuan Huang MD, Tsu-Yi Chao MD
}

A single transverse white band appeared on each of the fingernails of a 27-year-old woman after she received induction chemotherapy with daunorubicin and cytarabine for acute myeloid leukemia. We identified the bands, which did not fade with digital compression, as Mees lines (Figure 1A). In another woman, aged 41 years, fine, transverse depressed lines that were parallel and evenly spaced (Beau lines) developed on all of her fingernails while receiving triweekly docetaxel for metastatic breast cancer (Figure 1B).

Transverse linear lesions in nails can result from interruption in the growth of the nail matrix or changes in the colour in

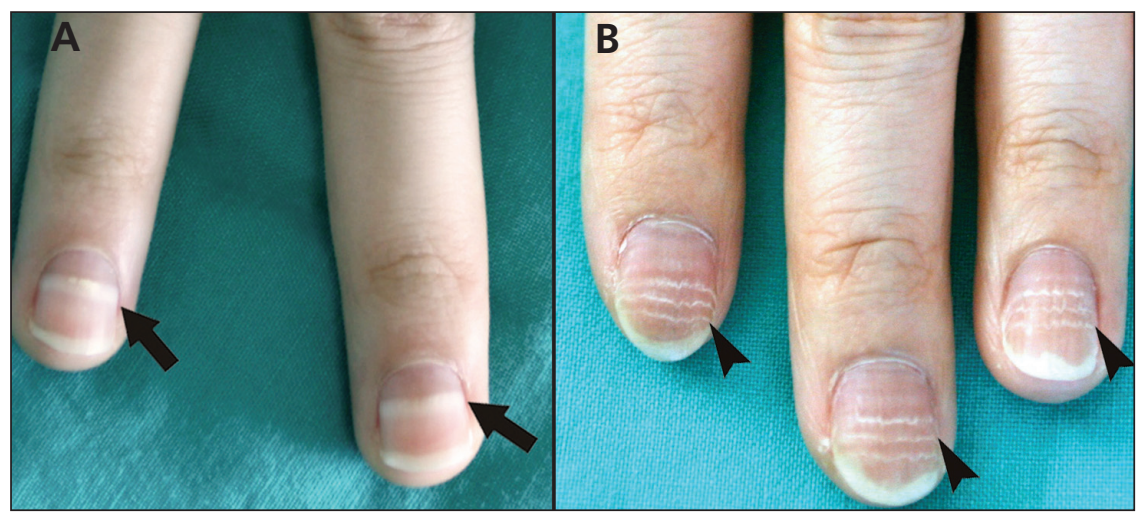

Figure 1: (A) Mees lines (arrows) in the fingernails of a 27-year-old woman. (B) Beau lines (arrowheads) in the fingernails of a 41 -year-old woman. the nail itself ${ }^{1}$ and may suggest an underlying systemic illness or the effect of toxins..$^{1-3}$ Changes in the nails are common in patients receiving chemotherapy, occurring in up to $44 \%$ of patients receiving taxanes. ${ }^{4}$ In a patient with no history of significant drug-related insult, such lesions may be important clues in the diagnosis of systemic illness.

Changes in the nails that are related to interruption of mitotic activity of the proximal nail matrix include Beau lines and onychomadesis. Beau lines appear as transverse depressions in the nail plates. The depth of the depression represents the extent of damage. The duration of the insult may be estimated by the longitudinal width of the damage; normal nail growth is about $1 \mathrm{~mm}$ every six to ten days. ${ }^{1-3}$ Onychomadesis results from complete toxicity of the matrix ${ }^{2}$ and can present with shedding of the nail or a sulcus that splits the nail plate into two parts. ${ }^{2,3}$ This condition is an extreme expression of Beau lines. ${ }^{3}$ Beau lines and onychomadesis may be caused by infection, surgery, trauma, Raynaud disease, pemphigus or chemotherapy (i.e., taxoids). ${ }^{1-3}$

In Mees lines (i.e., true leukonychia) a change occurs in the colour of the nail with no palpable ridges. ${ }^{1}$ Transverse, nonblanching white bands appear that run parallel to the lunula

From the Division of Hematology-Oncology, Department of Medicine, TriService General Hospital, National Defense Medical Center, Taipei, Taiwan

CMAJ 2009. DOI:10.1503/cmaj.090501 across the entire nail bed. ${ }^{1}$ The bands are caused by an insult to the distal nail matrix that does not lead to cessation in growth of the matrix, but instead causes parakeratosis of the ventral nail plate. ${ }^{2}$ Mees lines may be confused with Muehrcke lines (i.e., apparent leukonychia), which are paired white lines caused by vascular congestion in the nail bed. ${ }^{2}$ Muehrcke lines are easily distinguished from Mees lines because Muehrcke lines fade with digital compression and do not migrate with the growth of the nail. ${ }^{1-3}$ Mees lines are associated with arsenic poisoning, Hodgkin lymphoma, carcinoid tumours and chemotherapy (i.e., cyclophosphamide, vincristine and doxorubicin). Muehrcke lines result from liver disease, nephrotic syndrome, malnutrition and severe hypoalbuminemia (less than $20 \mathrm{~g} / \mathrm{L}) .^{1-3}$

This article has been peer reviewed.

Competing interests: None declared.

\section{REFERENCES}

1. Fawcett RS, Linford S, Stulberg DL. Nail abnormalities: clues to systemic disease. Am Fam Physician 2004;69:1417-24.

2. Hinds G, Thomas VD. Malignancy and cancer treatment-related hair and nail change. Dermatol Clin 2008;26:59-68.

3. Piraccini BM, Iorizzo M. Drug reactions affecting the nail unit: diagnosis and management. Dermatol Clin 2007;25:215-21.

4. Minisini AM, Tosti A, Sobrero AF, et al. Taxanes-induced nail changes: incidence, clinical presentation and outcome. Ann Oncol 2003;14:333-7. 